\title{
Labelfreie Detektion von Protein-DNA-Interaktionen durch elektrochemische Impedanzspektroskopie
}

\author{
Christoph Tersch, Fred Lisdat
}

\section{Zusammenfassung}

Es wird ein impedimetrisches Sensorsystem für den Nachweis von Protein-DNA-Wechselwirkungen vorgestellt. Der Sensor nutzt kurze Thiol-markierte DNA (ssDNA), die über Chemisorption auf Goldchipelektroden immobilisiert wird. Aus den Impedanzspektren wurde der Durchtrittswiderstand $\left(R_{c t}\right)$ als Kenngröße für die zu untersuchenden Wechselwirkungen gewählt. In Anwesenheit des Redoxsystems Ferro-/Ferrycyanid konnte eine Zunahme des Durchtrittswiderstandes nach der Immobilisierung und anschließender Hybridisierung auf der Sensoroberfläche registriert werden. Der Einsatz längerer Fänger-DNA (25mer im Vergleich zu 18-mer) führte zu einer Abnahme der Konzentration an immobilisierten Fänger-Strängen, aber auch zu einer Vergrößerung der Durchtrittswiderstände sowohl für ssDNA als auch dsDNA. Bei ähnlichen Oberflächenkonzentrationen ließ sich eine annähernd gleiche Sensitivität des Hybridisierungsnachweises im Vergleich zu 18-mer Fänger-Strängen erzielen.

Mit Hilfe des Elektrodensystems wurde die Nachweisbarkeit von Protein-DNA-Wechselwirkungen untersucht. Die Restriktion doppelsträngiger DNA durch die Restriktionsendonuklease BamHI konnte mit der Zyklovoltammetrie und markierungsfrei mit der Impedanzspektroskopie verfolgt werden. Des Weiteren wurde die sequenzspezifische Bindung des Transkriptionsfaktors NF-кB p50 anhand einer Abnahme von $\mathrm{R}_{\mathrm{ct}}$ impedimetrisch registriert.

\section{Abstract}

In this work, the applicability of an impedimetric DNA sensor has been investigated for the detection of protein-DNA interactions. The sensor is based on short thiol-modified single-stranded DNA, which is chemisorbed to gold chip electrodes. In the presence of the redox system ferri-/ferrocyanide impedance measurements show an increase in charge transfer resistance after immobilization and hybridization of ssDNA to the sensor surface. The use of a longer capture oligonucleotide (a 25-mer instead of an 18-mer) results in a decreasing probe concentration on the surface. Furthermore it causes an increase of the charge transfer resistance for both ssDNA and dsDNA. The hybridization event, however, can be detected with a similar sensitivity compared to an 18-mer (with the same surface concentration) and allows a good discrimination between ssDNA and dsDNA.

This electrode system is used to follow an enzyme reaction on the surface electrochemically. The cleavage of a double-stranded DNA by restriction endonuclease BamHI could be verified by cyclic voltammetry and impedance spectroscopy. The sequence specific DNAbinding of the transcription factor NF-KB p50 is found to cause a decrease in charge transfer resistance.

\section{Einleitung}

In den letzten Jahren hat der Einsatz von Nukleinsäuren als analytisches Werkzeug zur Identifizierung und Quantifizierung vieler Substanzen an Bedeutung gewonnen. Eine neue, interessante Art dieser affinen Biosensoren kann beispielsweise durch die Kombination von DNA-Schichten und elektrochemischen Transducern hergestellt werden. Verschiedene elektrochemische Methoden, wie Voltammetrie (Pänke et al. 2007; Bütow et al. 2010), Amperometrie (Hianik et al. 2001;
Loaiza et al. 2008) und Impedanzspektroskopie (Kafka et al. 2008; Park et al. 2009) finden bereits für die Detektion spezifischer DNA-Sequenzen Anwendung und erlauben die Konstruktion sensitiver, kleiner und kostengünstiger Sensoren (Drummond et al. 2003; Odenthal et al. 2007; Lucarelli et al. 2008). Die Einsatzfähigkeit dieser DNA-Biosensoren beschränkt sich jedoch nicht nur auf den Nachweis von Hybridisierungsvorgängen.

Eine Vielzahl an Studien belegen die Möglichkeit, DNA-Biosensoren auch für den Nachweis von niedermolekularen Substanzen einzusetzen (Evtyugin et al. 
2008; Erdem et al. 2002; Shah et al. 2008), die mit der DNA durch Interkalation, über Bindung in den Furchen doppelsträngiger DNA oder auf Grund elektrostatischer Wechselwirkungen interagieren (Labuda et al. 2010). Ein weiterer Bereich ist die Untersuchung von Protein-DNA-Wechselwirkungen, welchen eine vielfältige Bedeutung innerhalb von zellulären Prozessen, wie z. B. der Replikation, der Transkription, der Restriktion und der DNA-Reparatur, zukommt. Etablierte Methoden zur Detektion entsprechender Wechselwirkungen, wie der electromobility shift assay (Molloy 2000), der DNAse-footprinting assay (Bailly et al. 2005) oder Microarray-Techniken (Wang et al. 2003; Mukherjee et al. 2004) sind meist aufwändig, zeitintensiv oder benötigen ein radioaktives Label. Demzufolge ist die Entwicklung neuer, vorteilhafter Methoden für den Nachweis spezifischer Assoziationen zwischen Proteinen und DNA von besonderem Interesse. In letzter Zeit gelang es bereits einigen Arbeitsgruppen, elektrochemische Systeme zum indirekten aber auch direkten Nachweis von Protein-DNA Wechselwirkungen auf einer Elektrodenoberfläche einzusetzen. So kann durch die Bindung von Proteinen an dsDNA deren Basenpaarstapelung durch Herausdrehen von einzelnen Basen oder durch Biegung der Duplex beeinträchtigt werden, wodurch ein veränderter DNA-vermittelter Ladungstransfer hervorgerufen wird (Gorodetzky et al. 2008). Boon et al. (2002) nutzten dieses Prinzip zum Nachweis von Protein-DNA-Wechselwirkungen. Hierfür setzten sie Daunomycin als redoxaktiven Interkalator ein. Sowohl Proteinbindungen als auch enzymatische Reaktionen mit der DNA ließen sich dadurch anhand einer Abnahme des Stromflusses für Daunomycin zur Goldelektrode analysieren. Weiterhin stellen Proteine, die selbst elektroaktiv sind, eine interessante Alternative dar. Zum Beispiel konnte die elektrochemische Oxidation von Tyrosin- und Trypthophan-Resten innerhalb eines Proteins mittels Voltametrie zur Bindungsdetektion eingesetzt werden (Kerman et al. 2005). Ebenso wurde MutY, ein Basenaustausch-Reparatur-Enzym, untersucht. Elektrochemische Studien zeigten, dass die Bindung von MutY an DNA-modifizierten Goldelektroden mit einer Änderung des $[4 \mathrm{FeS}]^{3+/ 2+}$ Clusters assoziiert ist und so anhand einer DNA-vermittelten Redoxreaktion elektrochemisch detektiert werden kann (Boon et al. 2003).

Im Gegensatz zur Amperometrie und Voltammetrie, bei denen die eingesetzten Spannungen relativ hoch sind und dadurch potentialbedingte Schädigungen der Biomoleküle auftreten können, kann die elektrochemi- sche Impedanzspektroskopie (EIS) als eine relativ schonende Methode bezeichnet werden, die in den letzten Jahren vermehrt in den Fokus gerückt ist (Daniels et al. 2007; Lisdat et al. 2008; Pänke et al. 2008; Guan et al. 2004). Der Nachweis spezifischer Wechselwirkungen zwischen immobilisierten Biomolekülen und Analytmolekülen in Lösung kann prinzipiell durch Änderungen der Kapazität der elektrochemischen Doppelschicht oder des Durchtrittswiderstandes $\left(\mathrm{R}_{\mathrm{ct}}\right)$ analysiert werden. Einige Veröffentlichungen zeigen bereits erste Beispiele zur Nutzung dieses Systems für die Detektion von Protein-DNA-Wechselwirkungen (Chang et al. 2009; Ban et al. 2004).

Im Rahmen vorhergehender Arbeiten zeigten wir die Einsatzfähigkeit impedimetrischer DNA-Sensoren für den markierungsfreien Nachweis eines Metallinterkalators, eines Furchenbinders und eines Einzelstrang-DNABindeproteins (Witte et al. 2011). Ziel dieser Arbeit war die Detektion sequenzspezifischer Wechselwirkungen zwischen Proteinen und DNA. Hierzu wurden dsDNAmodifizierte Elektroden durch Immobilisierung und anschließende Hybridisierung von ssDNA präpariert. Da längere DNA-Stränge eine bessere Zugänglichkeit interagierender Proteine im Vergleich zu kurzen Strängen vermuten lassen, wurde zunächst die dsDNA-Ausbildung von 25-mer langen DNA-Strängen im Vergleich zu 18-meren impedimetrisch analysiert. Im Anschluss wurde die Funktionalität des Systems zur markierungsfreien Detektion von Protein-DNA-Wechselwirkungen verifiziert, wobei eine Restriktionsendonuklease (BamHI) und die sequenzspezifische Bindung eines Transkriptionsfaktors (NF-кB) untersucht wurden.

\section{Ergebnisse und Diskussion}

Zunächst wurde im Rahmen der Arbeit die Ausbildung doppelsträngiger DNA auf der Oberfläche von Goldchipelektroden unter Verwendung 25-mer langer DNA-Sequenzen charakterisiert. Daran anschließend wurden Untersuchungen zum elektrochemischen Nachweis sequenzspezifischer Interaktionen zweier Proteine mit immobilisierter dsDNA vorgenommen.

\section{Charakterisierung von DNA modifizierten \\ Goldelektroden}

Alle eingesetzten Elektroden wurden hinsichtlich der Effizienz der DNA Immobilisierung mit Hilfe der Zyklovoltammetrie nach der Hybridisierung Methylen- 

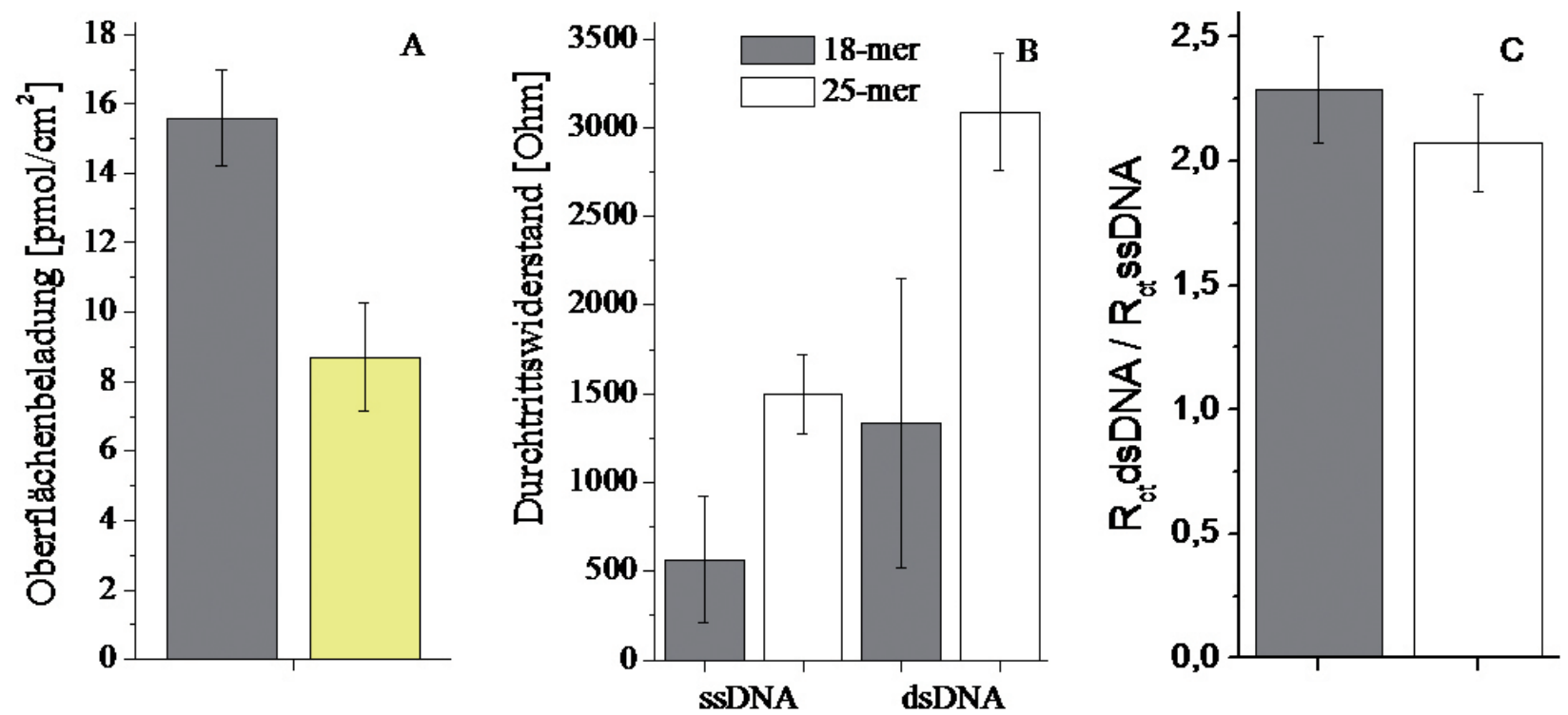

Abb. 1: (A) Vergleich der Oberflächenbeladung zwischen 18-mer (grau) und 25-mer (gelb) langen Fängersträngen unter gleichen Immobilisierungsund Hybridisierungsbedingungen. (B) Vergeich der Durchtrittswiderstände von ssDNA und dsDNA zwischen 18-mer (grau) und 25-mer (weiß) langen Oligonukleotiden bei vergleichbarer Oberflächenbelegung von $9 \mathrm{pmol} / \mathrm{cm}^{2}$. (C) Verhältnis der Durchtrittswiderstände $\mathrm{R}_{\mathrm{ct}}(\mathrm{dsDNA}) / \mathrm{R}_{\mathrm{ct}}(\mathrm{ssDNA})$ in Abhängigkeit von der Oligonukleotidlänge (grau: 18-mer, weiß: 25-mer) bei der gleichen Oberflächenbeladung $\left(9 \mathrm{pmol} / \mathrm{cm}^{2}\right)$. Die Impedanz wurde jeweils für drei Sensoren in einer Lösung aus $2 \mathrm{mM}$ Ferri-/Ferrocyanid in 0,1 M Natriumphosphatpuffer bei pH 7 bestimmt.

blau(MB)-markierter Target-Stränge beurteilt (Pänke et al. 2007). Das nach der Hybridisierung in Elektrodennähe befindliche redoxaktive $\mathrm{MB}$ kann voltammetrisch erfasst werden, wodurch eine Quantifizierung der hybridisierungsfähigen Fänger-Stränge auf der Elektrodenoberfläche möglich ist. Zur impedimetrischen Charakterisierung der Immobilisierung und Hybridisierung von DNA wurden Impedanzmessungen in Anwesenheit des Redoxsystems Kaliumhexacyanoferrat (II/III) durchgeführt. Verglichen mit einer unmodifizierten Elektrode resultierte die Immobilisierung von ssDNA in einer Zunahme der Impedanz. Analog dazu führte auch eine Hybridisierung zu einer Signalzunahme. Beide Effekte lassen sich dadurch erklären, dass die elektrochemische Redoxreaktion der Kaliumhexacyanoferrationen aufgrund der Akkumulation von negativer Ladung auf der Oberfläche und der damit verbundenen verstärkten elektrostatischen Abstoßung behindert wird. Die Impedanzspektren wurden durch eine Anpassung an das Randles-Ersatzschaltbild ausgewertet und der Durchtrittswiderstand als analytische Messgröße gewählt.

Ein Ziel dieser Arbeit war die Untersuchung des Einflusses der DNA-Stranglänge auf die Sensitivität des Hybridisierungsnachweises (Steel et al. 2000). Durch den Einsatz längerer Fänger-Stränge soll eine bessere Zugänglichkeit interagierender Biomoleküle erreicht werden. Dieser Fragestellung nachkommend wurden anstatt der bisher eingesetzten 18-mer langen DNA-
Stränge 25-mer DNA-Stränge genutzt (Witte et al. 2011). Hierbei wurde festgestellt, dass der Einsatz längerer DNA-Stränge unter gleichen Bedingungen zu einer Verringerung der Menge an immobilisierter DNA führt (siehe Abb. 1A). Dies lässt sich dadurch erklären, dass nicht nur die Thiol-Gruppen mit der Goldoberfläche interagieren, sondern der gesamte DNA-Strang. Erst der anschließende Passivierungsschritt mit 4-Mercapto1-butanol löst das DNA-Rückgrat von der Oberfläche und richtet die Stränge zur Lösung aus. Demzufolge blockieren während der Immobilisierung längere DNAStränge einen größeren Bereich auf der Oberfläche und limitieren somit die Zugänglichkeit für weitere FängerStränge.

\begin{tabular}{|l|l|l|}
\hline ssDNA & $\begin{array}{l}\text { Modifi- } \\
\text { kation }\end{array}$ & Sequenz $\left(5^{\prime} \rightarrow 3^{\prime}\right)$ \\
\hline Fänger 1 & $5^{\prime}$-SH & GTC AGC TCT ATC CAT AGG \\
\hline Target 1 & $5^{\prime}$-MB & CCT ATG GAT AGA GCT GAC \\
\hline Target $1 \mathrm{a}$ & & CCT ATG GAT AGA GCT GAC \\
\hline Fänger 2 & $5^{\prime}$-SH & GTC AGT CGG ATC CAT ACA AGT TCG C \\
\hline Target 2 & $5^{\prime}$-MB & GCG AAC TTG TAT GGA TCC GAC TGA C \\
\hline Target 2a & & GCG AAC TTG TAT GGA TCC GAC TGA C \\
\hline Fänger 3 & $5^{\prime}$-SH & GAC GAT TGA GGG GAC TTT CCC AGG C \\
\hline Target 3 & $5^{\prime}$-MB & GCC TGG GAA AGT CCC CTC AAT CGT C \\
\hline Target 3a & & GCC TGG GAA AGT CCC CTC AAT CGT C \\
\hline
\end{tabular}

Tab. 1: eingesetzte DNA Sequenzen 
Durch die impedimetrischen Messungen konnte weiterhin gezeigt werden, dass die Länge der DNA-Stränge Einfluss auf den Durchtrittswiderstand hat, sowohl für den ssDNA- als auch für dsDNA-Zustand. Unter Berücksichtigung gleicher Oberflächenbelegungen an DNA konnte bei höherer Nukleotidanzahl eine Zunahme des Durchtrittswiderstandes verfolgt werden, was auf eine verstärkte Akkumulation von negativer Ladung auf den Elektroden zurückzuführen ist. Für die Impedanzspektren von 25-mer langen DNA-Sequenzen wurden Signalerhöhungen von $166 \%$ für ssDNA und $133 \%$ für dsDNA im Vergleich zu 18-meren registriert (Abb. 1B). Bei gleicher Oberflächenbelegung konnte dennoch für 25 mer und 18-mer lange DNA-Stränge eine ähnliche Sensitivität des impedimetrischen DNA-Nachweises erzielt und somit eine gute Differenzierung zwischen ssDNA und dsDNA auf der Elektrodenoberfläche gewährleistet werden (Abb. 1C).

Im Gegensatz zum Durchtrittswiderstand konnten nur geringe Änderungen der Kapazität von $6 \%$ für 25-mer DNA und $3 \%$ für 18-mer DNA nach einer Hybridisierungsreaktion detektiert werden. Weiterhin wurde beobachtet, dass eine vollständige Denaturierung von 25-mer dsDNA mit den für 18-mer dsDNA verwendeten Denaturierungsbedingungen nicht realisierbar ist (Kafka et al. 2008). Voltammetrische Messungen bewiesen, dass eine Verlängerung der DNA zur Ausbildung stabilerer dsDNA führt. Durch eine Verlängerung der Inkubationszeit mit der zur Denaturierung eingesetzten Harnstofflösung von 30 s auf 10 - 20 min ließen sich dennoch alle 25-mer dsDNA-Stränge auf der Elektrodenberfläche denaturieren und der Sensor sich somit für eine weitere Hybridisierung regenerieren.

Enzymatische Restriktion durch die Endonuklease BamHI

Neben dem Nachweis von Nukleinsäuren bietet der Einsatz von DNA-Monoschichten ebenso eine Plattform für die elektrochemische Analyse von Protein-DNAWechselwirkungen. Diese spezifischen Interaktionen sind vor allem innerhalb zellulärer Prozesse, wie z. B. der DNA-Replikation, der Transkription und der Reparatur, von besonderer Bedeutung. Zu wichtigen Werkzeugen der modernen Molekularbiologie zählen unter anderem die Restriktionsendonukleasen. Sie ermöglichen die gezielte Herstellung von DNA-Fragmenten, die dann isoliert und zu neuen Konstruktionen zusammengesetzt werden können.
Im Rahmen dieser Arbeit wurde unter Verwendung eines 25-mer Elektrodensystems die sequenzspezifische Restriktion immobilisierter dsDNA durch die Restriktionsendonuklease BamHI untersucht. Hierzu wurden Messungen mit Hilfe der Zyklovoltammetrie sowie der Impedanzspektroskopie durchgeführt. BamHI erkennt als Dimer spezifisch die Sequenz 5'-GGATCC-3' und katalysiert in Anwesenheit von Magnesiumionen als Cofaktor die Restriktion doppelsträngiger DNA zwischen den Guaninbasen (Engler et al. 2001).

Für den voltammetrischen Nachweis der DNA-Restriktion wurden spezifische ssDNA-modifizierte Elektroden mit komplementärer MB-markierter ssDNA hybridisiert. Durch die Bindung des MB lässt sich anhand der Peakströme (siehe Abb. 2A(a)) die Menge an dsDNA auf der Elektrodenoberfläche quantifizieren. Nach $3 \mathrm{~h}$ Behandlung der dsDNA-modifizierten Elektrode mit $1 \mathrm{U} / \mu \mathrm{l}$ BamHI konnte ein vollständiger Verlust des MBRedoxsignals nachgewiesen werden (Abb. 2A(b)). Somit ließ sich auf eine durch BamHI katalysierte Restriktion der dsDNA auf der Elektrode schließen, da durch die Strangtrennung MB-markierte DNA-Fragmente entfernt werden und folglich kein MB-charakteristischer Redoxpeak registriert werden kann.

Weitere Untersuchungen zeigten, dass die Effizienz der enzymatischen Restriktion von der Inkubationszeit abhängt (Abb. 2B). Nach der Inkubation des Restriktionsansatzes auf der Elektrode für 15 bis 180 min ist eine stetige Abnahme der Redoxpeaks für MB nachzuweisen. Bereits nach einer Inkubation mit BamHI für 15 min ist ein signifikanter Stromabfall zu verzeichnen, der mit einer weiteren Verlängerung der Zeit allmählich zunimmt. Eine vollständige Restriktion der dsDNA auf der Elektrodenoberfläche ist durch die Inkubation von $1 \mathrm{U} / \mathrm{\mu l}$ BamHI für $120 \mathrm{~min}$ bei $37^{\circ} \mathrm{C}$ nachweisbar. Demzufolge wurden alle weiteren Untersuchungen unter diesen Bedingungen durchgeführt.

Im Weiteren wurde die Sequenzspezifität der BamHIkatalysierten Restriktion auf der Elektrodenoberfläche verifiziert. Hierzu wurden Goldchipelektroden mit dsDNA präpariert, welche nicht die spezifische Erkennungssequenz für BamHI enthält (Fänger 3/Target 3). Analog zu den vorhergehenden Versuchen ist aus Abb. 2C(a) ein charakteristischer Redoxpeak für MB nach der Hybridisierung-MB-markierter Target-Stränge zu erkennen. Nach der Inkubation der dsDNA-modifizierten Elektrode für 120 min mit BamHI ist jedoch nur eine geringe Abnahme der Peakströme um 15\% zu verzeichnen (Abb. 2C(b)). Dieses Ergebnis lässt auf eine hohe 

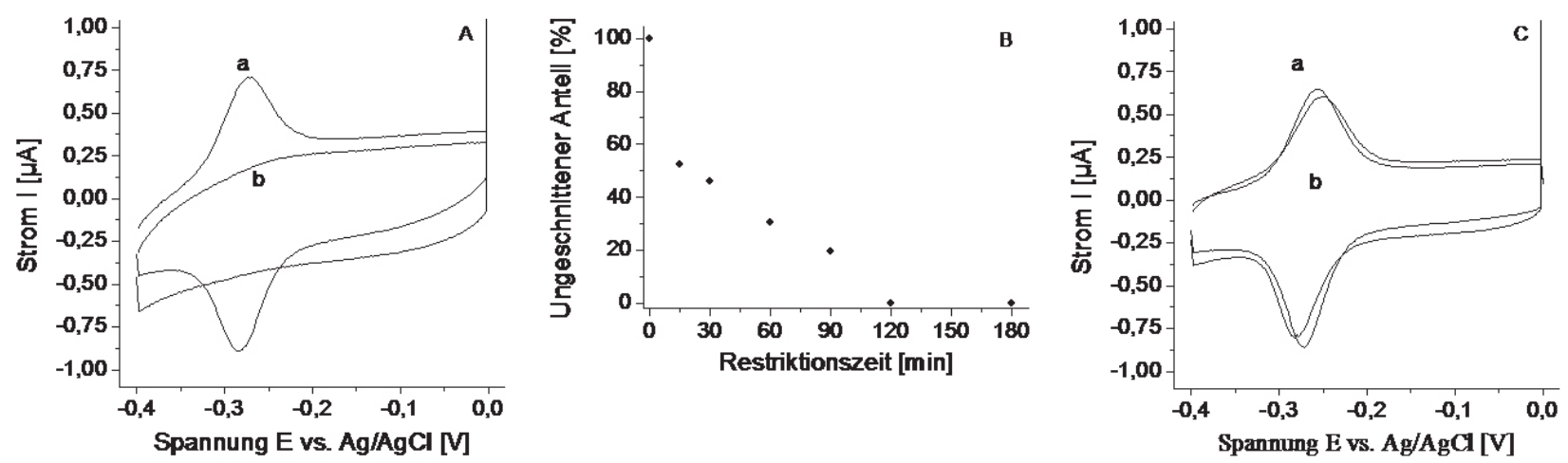

Abb. 2: (A) Cyclovoltammogramme der mit für BamHI spezifischen dsDNA-modifizierten Elektroden vor (a) und nach (b) der Behandlung mit einer BamHI-Endonuklease-Lösung (1 U/ $\mu$ l). (B) Prozentuale Darstellung des unveränderten dsDNA-Anteils auf der Elektrodenoberfläche (cyclovoltammetrische Bestimmung) als Funktion der Restriktionszeit. (C) Cyclovoltammogramme der mit für BamHI unspezifischen dsDNA modifizierten Elektroden vor (a) und nach (b) der Behandlung mit einer BamHI Endonuklease Lösung (1 U/ $\mu \mathrm{l})$. Alle Voltammogramme wurden in 0,1 M Natriumphosphatpuffer $\mathrm{pH} 7$ bei einer Scanrate von $0.1 \mathrm{~V} / \mathrm{s}$ aufgenommen.

Spezifität der BamHI-katalysierten Restriktion schließen, auch wenn sich die Nukleinsäuren in unmittelbarer Nähe zu einer Elektrode befindet.

Anschließend wurde die elektrochemische Impedanzspektroskopie zur markierungsfreien Detektion der sequenzspezifischen Restriktion von dsDNA durch BamHI eingesetzt. Zu diesem Zweck wurde die Sensoroberfläche zunächst nach der Quantifizierung der ssDNA-Immobilisierung mittels Zyklovoltammetrie durch einen Denaturierungsschritt mit Harnstofflösung regeneriert. Im Anschluss erfolgten die impedimetrischen Messungen.

Voruntersuchungen zeigten, dass die Anwesenheit von DTT im Restriktionspuffer zu deutlichen Änderungen der Impedanz der DNA/MCB-modifizierten Elektrode führt, ohne dass BamHI gegenwärtig ist. Aus diesem Grund wurde DTT für alle folgenden impedimetrischen Messungen aus dem Restriktionspuffer entfernt. Auch in diesem DTT-freien Restriktionspuffer konnte mit Hilfe der zyklovoltammetrischen Methode eine hohe katalytische Aktivität der Endonuklease BamHI nachgewiesen werden.

In Abb. 3A sind die Nyquist-Plots einer dsDNA-modifizierten Elektrode vor und nach der Behandlung mit $1 \mathrm{U} / \mu \mathrm{l}$ BamHI dargestellt. Nach der Inkubation ist mit $1005 \Omega$ (b) eine deutlich Abnahme des Durchtrittswiderstandes im Vergleich zum Ausgangszustand mit $2994 \Omega$ (a) für eine dsDNA-modifizierte Elektrode zu verzeichnen. Zusätzlich sind in Abb. 3B die relativen Durchtrittswiderstandsänderungen für dsDNA-modifizierte Elektroden nach der Inkubation mit dem Restriktionsansatz mit und ohne die spezifische Erkennungssequenz für BamHI zusammengefasst. Die Restriktion der dsDNA führte zu einer signifikanten Abnahme von $\mathrm{R}_{\mathrm{ct}}$, was auf die verringerte negative Ladung auf der Elektrodenoberfläche und den dadurch verbesserten Ladungstransfer zurückzuführen ist. Im Vergleich dazu zeigten die Versuche mit dsDNA ohne spezifische Erkennungssequenz für BamHI keine signifikante Änderung von $\mathrm{R}_{\mathrm{ct}}$ nach Inkubation mit BamHI. Schlussfol-
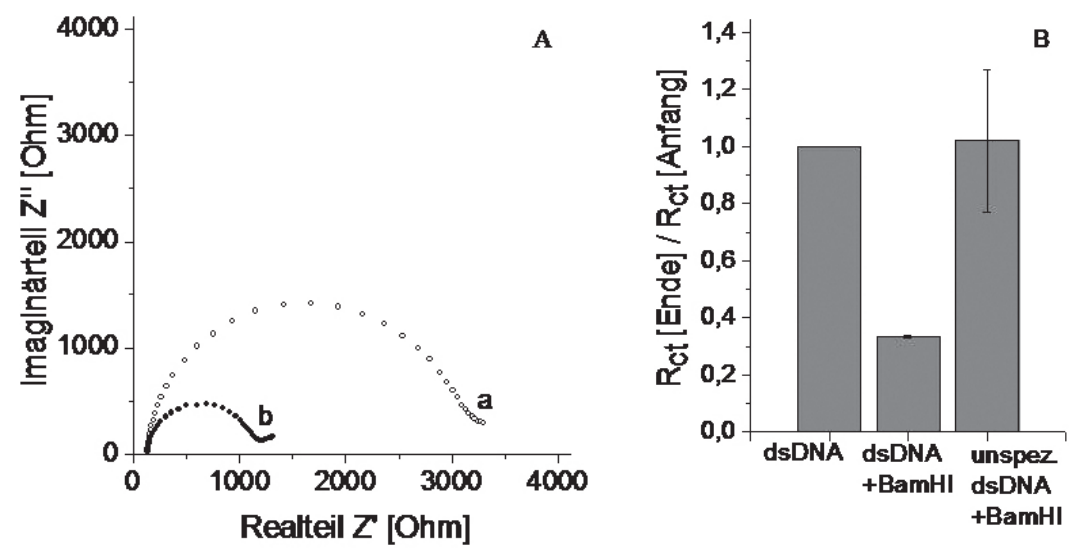

Abb. 3: (A) Impedanzspektren der mit für BamHI spezifischen dsDNA-modifizierten Elektroden vor (a) und nach (b) der Behandlung mit

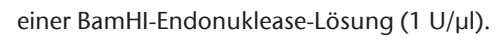
(B) Verhältnis der Durchtrittswiderstände $R_{c t}$ (nach) / $\mathrm{R}_{\mathrm{ct}}$ (vor) jeweils bestimmt nach bzw. vor der Elektrodenbehandlung mit der BamHILösung für Elektroden mit einer für BamHI spezifischen bzw. unspezifischen dsDNA-Erkennungssequenz-Modifikation. Die Impedanz wurde jeweils für drei Sensoren in einer Lösung aus $2 \mathrm{mM}$ Ferri-/Ferrocyanid in 0,1 M Natriumphosphatpuffer bei $\mathrm{pH} 7$ bestimmt. 
gernd zeigte diese Versuchsreihe, dass es möglich ist, die enzymatische Restriktion doppelsträngiger DNA durch die Endonuklease BamHI markierungsfrei mit Hilfe der elektrochemischen Impedanzspektroskopie nachzuweisen.

\section{Impedimetrische Detektion der DNA-Bindung} von NF-Kappa B p50

Neben enzymatischen Wechselwirkungen mit DNA sind auch Bindungsereignisse an DNA, wie zum Beispiel von Transkriptionsfaktoren, von besonderem Interesse. Transkriptionsfaktoren wie NF-kB sind an einer Vielzahl von biologischen Prozessen, wie Entzündungs- und Immunabwehr-Mechanismen, der Apoptose oder der Zellproliferation, beteiligt (Tisné et al. 1999). NF-кB beschreibt eine Gruppe von fünf strukturell ähnlichen Proteinen, die zur Familie der NF-кB/Rel-Proteine gezählt werden (Hayden et al. 2004). Deren Gemeinsamkeit ist eine Domäne von ca. 300 Aminosäuren, die sogenannte Rel-Homologie Domäne, welche an der Dimerisierung und der DNA-Bindung beteiligt ist. Jeweils zwei Untereinheiten können in unterschiedlichen Kombinationen aneinander binden und so z. B. p50/p65-Heterodimere oder p50/p50-Homodimere ausbilden (Gosh et al. 1995). Im Rahmen dieser Arbeit wurde die DNA-Bindung von p50/p50-Homodimeren mit Hilfe der Impedanzspektroskopie untersucht. Für diesen Zweck wurden Goldchipelektroden mit dsDNA (Fänger 3/Target 3) präpariert, welche die spezifische Erkennungssequenz für NF-кB p50 5'-GGGRNNYYCC-3' enthielt (wobei R für Adenin oder Guanin, Y für Thymin oder Cytosin und N für eine beliebige der vier Basen steht) (Sif et al. 1993).

Aus Abb. 4A wird deutlich, dass die Inkubation einer 25-mer dsDNA-modifizierten Elektrode mit $33 \mu \mathrm{g} / \mathrm{ml}$ NF-кB p50 zu einer Abnahme von $\mathrm{R}_{\mathrm{ct}}$ um 13 \% führt,

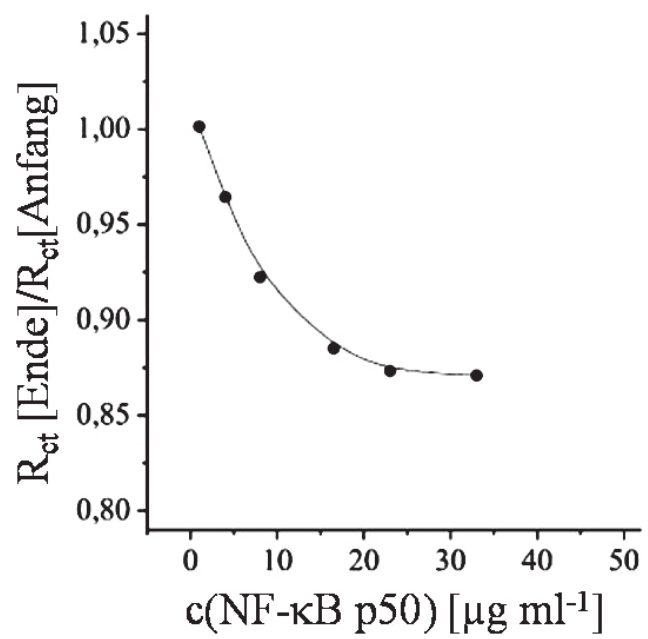

Abb. 5: Verhältnis der Durchtrittswiderstände $R_{c t}$ (nach)/ $R_{c t}$ (vor) jeweils bestimmt nach bzw. vor der Sensorinkubation mit verschieden kon-

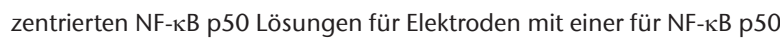
spezifischen dsDNA-Erkennungssequenz. Die Impedanz wurde jeweils für drei Sensoren in einer Lösung aus $2 \mathrm{mM}$ Ferri-/Ferrocyanid in 0,1 M Natriumphosphatpuffer bei $\mathrm{pH} 7$ bestimmt.

hingegen jedoch nur in einer kapazitiven Änderung des Sensors von $2 \%$ resultiert. Im Gegensatz dazu zeigten Elektroden mit dsDNA ohne spezifische Erkennungssequenz für NF- $\kappa \mathrm{B}$ nach der Inkubation mit dem Protein keine Änderung in der Impedanz. Weiterhin konnte auch nach der Inkubation mit dem Bindungspuffer allein nur eine minimale Zunahme von $\mathrm{R}_{\mathrm{ct}} \mathrm{um}$ $4 \%$ registriert werden. Die Ergebnisse verdeutlichen, dass die spezifische DNA-Bindung von NF-кB p50 mit Hilfe der Impedanzspektroskopie markierungsfrei detektierbar ist und unspezifische Bindungen des Proteins an DNA auszuschließen sind. Darauf aufbauend wurde unter Verwendung von $1 \mu \mathrm{g} / \mathrm{ml}$ bis $33 \mu \mathrm{g} / \mathrm{ml}$ NF- $\kappa$ B p50 versucht, eine konzentrationsabhängige Änderung des Widerstandes aufzuzeigen. Die resultierende Bindungskurve ist in Abb. 5 dargestellt und lässt eine definierte
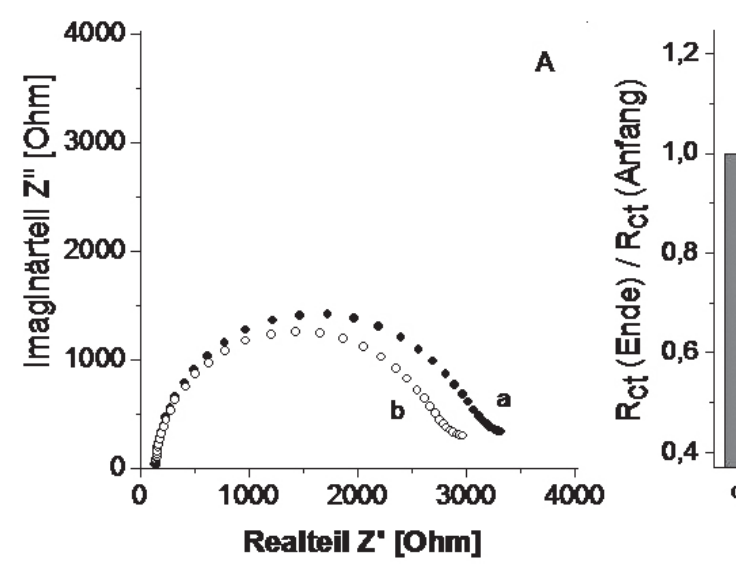

B

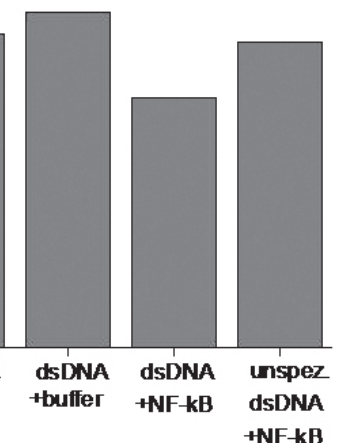

Abb. 4: (A) Impedanzspektren der mit für NF-кB spezifischen dsDNA modifizierten Elektroden vor (a) und nach (b) der Behandlung mit einer $33 \mu \mathrm{g} / \mathrm{ml}$ NF- $\mathrm{B}$ p 50 Lösung. (B) Verhältnis der Durchtrittswiderstände $R_{c t}$ (nach)/ $R_{c t}$ (vor) jeweils bestimmt nach bzw. vor der Elektrodenbehandlung mit einer $33 \mu \mathrm{g} / \mathrm{ml}$ NF-кB p50 Lösung für Elektroden mit einer für NF-кB p50 spezifischen bzw. unspezifischen dsDNAErkennungssequenz-Modifikation. Die Impedanz wurde jeweils für drei Sensoren in einer Lösung aus 2mM Ferri-/Ferrocyanid in 0,1M Natriumphosphatpuffer bei $\mathrm{pH} 7$ bestimmt. 
Abnahme von $\mathrm{R}_{\mathrm{ct}}$ mit steigender NF-кB p50 Konzentration erkennen.

Die Abnahme von $\mathrm{R}_{\mathrm{ct}}$ nach der Protein-DNA-Bindung kann durch die NF-кB-Bindung hervorgerufene Veränderung der Ladungssituation erklärt werden. Die spezifische DNA-Bindung von NF-кB p50 Homodimeren resultiert einerseits aus Wechselwirkungen mit den Nukleobasen der DNA, zusätzlich erfolgt andererseits auch eine Interaktion mit dem DNA-Rückgrat durch verschiedene Reste in den Schleifen der NF-кB Sekundärstruktur, wovon 16 positiv geladen sind (Gosh et al. 1995; Michalopoulos et al. 1999). Für die DNA-Bindung von NF-кB p50/p65 Heterodimere ist eine durch die Proteinbindung hervorgerufene Neutralisation der negativen Ladung des DNA-Rückgrats beschrieben (Tisné et al. 1999). Da die DNA-Wechselwirkung auch bei p50Homodimeren über die Rel-Homologie Domäne erfolgt, ist auch hier ein Neutralisationseffekt anzunehmen. In diesem Fall würde die verringerte negative Ladung auf der Elektrodenoberfläche den Ladungsaustausch zwischen dem Kaliumhexacyanoferrat(II/III)-Redoxsystem und der Elektrode verstärken, was der detektierten Abnahme von $\mathrm{R}_{\mathrm{ct}}$ entspräche.

\section{Danksagung}

Wir danken dem BMBF (Projekt-Nr. 13N9593) für die finanzielle Unterstützung.

\section{Literatur}

Bailly, C., Kluza, J., Martin, C., Ellis, T., Waring, M. J. (2005): DNase I Footprinting of Small Molecule Binding Sites on DNA. Methods in Molecular Biology, 288, 319-342.

Ban, C., Chung, S., Park, D. S., Shim, Y.B. (2004): Detection of proteinDNA interaction with a DNA probe: distinction between singlestrand and double-strand DNA-protein interaction. Nucleic Acids Research, 32, e110.

Boon, E. M., Livingston, A. L., Chmiel, N. H., Barton, J. K. (2003): DNA-mediated charge transport for DNA repair. PNAS, 100, 12543-12547.

Boon, E. M., Salas, J. E., Barton, J. K. (2002): An electrical probe of protein-DNA interactions on DNA-modified surfaces. Nature Biotechnology, 20, 282-286.

Buetow, S., Lisdat, F. (2010): Parallel Detection of Different DNA Sequences on One Gold Electrode. Electroanalysis, 22, 931-937.

Chang, H., Li, J. (2009): Electrochemical impedance probing of transcriptional TATA binding protein based on TATA box site-specific binding. Electrochemistry Communications, 11, 2101-2104.

Conolly, B. A., Rider, P. (1985): Chemical Synthesis of oligonucleotides containing a Free Sulfhydryl-Group and Subsequent Attachment of Thiol Specific Probes. Nucleic Acids Research, 13, 4485-4502.
Daniels, J. S., Pourmand, N. (2007): Label-free impedance biosensors: Opportunities and challenges. Electroanalysis, 19, 1239-1257. Drummond, T. G., Hill, M. G., Barton, J. K. (2003): Electrochemical DNA sensors. Nature Biotechnology, 21, 1192-1199.

Engler, L. E., Sapienza, P., Dorner, L. F., Kucera, R., Schildkraut, I., JenJacobson, L. (2001): The energetics of the interaction of BamHI endonuclease with its recognition site GGATCC. Journal of Molecular Biology, 307, 619-636.

Erdem, A., Ozsoz, M. (2002): Electrochemical DNA biosensors based on DNA-drug interactions. Electroanalysis, 14, 965-974.

Evtyugin, G. A., Budnikov, G. K., Porfi'eva, A. V. (2008): Electrochemical DNA-sensors for determining biologically active lowmolecular compounds. Russian Journal of General Chemistry, 78, 2489-2506

Ghosh, G., Vanduyne, G., Ghosh, S., Sigler, P. B. (1995): Structure of NF-Kappa-B P50 Homodimer bound to a Kappa-B site. Nature, 373, 303-310

Gorodetsky, A. A., Buzzeo, M. C., Barton, J. K. (2008): DNA-Mediated Electrochemistry. Bioconjugate Chemistry, 19, 2285-2296.

Guan, J. G., Miao, Y. Q., Zhang, Q. J. (2004): Impedimetric biosensors. Journal of Bioscience and Bioengineering, 97, 219-226.

Hayden, M. S., Ghosh, S. (2004): Signaling to NF-kappa B. Genes \& Development, 18, 2195-2224.

Hianik, T., Gajdos, V., Krivanek, R., Oretskaya, T., Metelev, V., Volkov, E., Vadgama, P. (2001): Amperometric detection of DNA hybridization on a gold surface depends on the orientation of oligonucleotide chains. Bioelectrochemistry, 53, 199-204.

Kafka, J., Paenke, O., Abendroth, B., Lisdat, F. (2008): A label-free DNA sensor based on impedance spectroscopy. Electrochimica Acta, $53,7467-7474$.

Kerman, K., Morita, Y., Takamura, Y., Tamiya, E. (2005): Escherichia coli single-strand binding protein-DNA interactions on carbon nanotube-modified electrodes from a label-free electrochemical hybridization sensor. Analytical and Bioanalytical Chemistry, 381, 1114-1121.

Labuda, J., Oliveira Brett, A. M., Evtugyn, G., Fojta, M., Mascini, M., Ozsoz, M., Palchetti, I., Palecek, E., Wang, J.: Electrochemical nucleic acid-based biosensors: Concepts, terms, and methodology (IUPAC Technical Report). Pure and Applied Chemistry, 82, 1161-1187.

Lisdat, F., Schaefer, D. (2008): The use of electrochemical impedance spectroscopy for biosensing. Analytical and Bioanalytical Chemistry, 391, 1555-1567.

Loaiza, O. A., Campuzano, S., Guzman-Vazquez de Prada, A., Pedrero, M., Pingarron, J. M. (2008): Amperometric DNA quantification based on the use of peroxidase-mercaptopropionic acid-modified gold electrodes. Sensors and Actuators B-Chemical, 132, 250-257.

Lucarelli, F., Tombelli, S., Minunni, M., Marrazza, G., Mascini, M. (2008): Electrochemical and piezoelectric DNA biosensors for hybridisation detection. Analytica Chimica Acta, 609, 139-159.

Meunier-Prest, R., Bouyon, A., Rampazzi, E., Raveau, S., Andreoletti, P., Cherkaoui-Malki, M.: Electrochemical probe for the monitoring of DNA-protein interactions. Biosensors \& Bioelectronics, 25, 2598-2602.

Michalopoulos, I., Hay, R. T. (1999): Role of the conserved lysine 80 in stabilisation of NF-kappa B p50 DNA binding. Nucleic Acids Research, 27, 503-509.

Molloy, P. L. (2000): Electrophoretic Mobility Shift Assays. Methods in Molecular Biology, 130, 235-246. 
Mukherjee, S., Berger, M. F., Jona, G., Wang, X. S., Muzzey, D., Snyder, M., Young, R. A., Bulyk, M. L. (2004): Rapid analysis of the DNAbinding specificities of transcription factors with DNA microarrays. Nature Genetics, 36, 1331-1339.

Odenthal, K. J., Gooding, J. J. (2007): An introduction to electrochemical DNA biosensors. Analyst, 132, 603-610.

Paenke, O., Kirbs, A., Lisdat, F. (2007): Voltammetric detection of single base-pair mismatches and quantification of label-free target ssDNA using. Biosensors \& Bioelectronics, 22, 2656-2662.

Paenke, O., Balkenhohl, T., Kafka, J., Schafer, D., Lisdat, F. (2008): Impedance spectroscopy and biosensing. Advances in biochemical engineering/biotechnology, 109, 195-237.

Park, J.-Y., Park, S.-M. (2009): DNA Hybridization Sensors Based on Electrochemical Impedance Spectroscopy as a Detection Tool. Sensors, 9, 9513-9532.

Riddles, P.W., Andrews, R. K., Blakeley, R. L., Zerner, B. (1983): Jack bean urease. 6. determination of thiol and disulfide content reversible inactivation of the enzyme by the blocking of the unique cysteine residue. Biochimica \& Biophysica Acta, 743, 115-120.

Shah, A., Khan, A. M., Qureshi, R., Ansari, F. L., Nazar, M. F., Shah, S. S. (2008): Redox behavior of anticancer chalcone on a glassy carbon electrode and evaluation of its interaction parameters with DNA. International Journal of Molecular Sciences, 9, 1424-1434.

Sif, S., Gilmore, T.D. (1993): NF-Kappa-B P100 is one of the highmolecular-weight proteins complexed with the V-REL oncoprotein in transformed chicken spleen-cells. Journal of Virology, 67, 7612-7617.

Steel, A. B., Levicky, R. L., Herne, T. M., Tarlov, M. J. (2000): Immobilization of nucleic acids at solid surfaces: Effect of oligonucleotide length on layer assembly. Biophysical Journal, 79, 975-981.

Tisne, C., Delepierre, M., Hartmann, B. (1999): How NF-kappa B can be attracted by its cognate DNA. Journal of Molecular Biology, 293, 139-150

Wang, J., Bai, Y. F., Li, T. X., Lu, Z. (2003): DNA microarrays with unimolecular hairpin double-stranded DNA probes: fabrication and exploration of sequence-specific DNA/protein interactions. Journal of Biochemical and Biophysical Methods, 55, 215-232.

Witte, C., Lisdat, F. (2011): Direct Detection of DNA and DNA-Ligand Interaction by Impedance Spectroscopy. Electroanalysis, 23, 339-346.

\section{Autoren}

Christoph Tersch, M. Sc.

AG Biosystemtechnik

Technische Hochschule Wildau [FH]

christoph.tersch@googlemail.com

Prof. Dr. rer. nat. habil. Fred Lisdat AG Biosystemtechnik

Technische Hochschule Wildau [FH] fred.lisdat@th-wildau.de 